Journal of Clinical Investigation

Vol. 41, No. 4, 1962

\title{
PATHOGENESIS OF THE COAGULATION DEFECT DEVELOPING DURING PATHOLOGICAL PLASMA PROTEOLYTIC ("FIBRINOLYTIC") STATES. \\ I. THE SIGNIFICANCE OF FIBRINOGEN PROTEOLYSIS AND CIRCULATING FIBRINOGEN BREAKDOWN PRODUCTS *
}

\author{
By ANTHONY P. FLETCHER, NORMA ALKJAERSIG AND SOL SHERRY \\ (From the Department of Medicine, Washington University School of Medicine, \\ St. Louis, Mo.)
}

(Submitted for publication July 13, 1961 ; accepted December 21, 1961)

A clinical syndrome characterized by hypofibrinogenemia, a coagulation defect, often an associated severe hemorrhagic diathesis, and manifestations of whole blood or plasma "fibrinolysis" (spontaneous lysis of whole blood or plasma clots) has long been recognized (1). The conditions may develop: following surgery $(2,3)$, particularly thoracic surgery $(4,5)$; be associated with obstetric complications $(6,7)$, notably abruptio placenta (8-11); develop rarely during the course of neoplastic disease (12), but more commonly if the prostate is involved $(13,14)$; complicate the course of hepatic cirrhosis (15-18) or certain other medical conditions, most frequently in their terminal stages.

Since the syndrome may complicate many disease conditions and is most frequently manifested by rapid whole blood clot lysis, it often has been described as a "pathological fibrinolytic state" or as "fibrinolysis as a disease state." However, since the phenomenon involves the action of proteolytic rather than strictly fibrinolytic enzymes, descriptive terms involving the word proteolytic rather than fibrinolytic are clearly preferable. Such terms as "excessive plasma proteolytic activity" or "pathological proteolytic state" not only define the condition more accurately, but focus attention on its wider ramifications.

Hitherto the study of the syndrome in humans has been difficult for it occurs more frequently as

* This work was supported by a grant from the $\mathrm{Na}$ tional Heart Institute (H3745), United States Public Health Service, Bethesda, Md. Presented in part at the Fifty-first National Meeting of the American Society for Clinical Investigation, Atlantic City, N. J., May, 1959 (J. clin. Invest. 1959, 38, 1005) and at the Thirty-third Annual Meeting of the Central Society for Clinical Research, Chicago, Ill., October, 1960 (J. Lab. clin. Med. $1960,56,813)$. an acute rather than as a chronic state and when recognized clinically is usually associated with a severe hemorrhagic diathesis requiring urgent treatment. Consequently the opportunity for clinical investigation has been severely limited and most studies have been made in vitro or in animals.

Recently the iatrogenic induction of this syndrome, arising secondarily to the treatment of patients with acute thromboembolic complications by enzymatic means, has both enhanced its importance and offered unique opportunities for its investigation (19-23). Data on the coagulation defect and the associated hemorrhagic diathesis resulting from the therapeutic infusion of plasminogen activators suggested that the pathogenesis of the coagulation defect was related directly or indirectly to the proteolysis of fibrinogen and the production of an inhibitor interfering at the stage of fibrinogen-fibrin conversion $(19,24)$.

It will be the purpose of this communication to describe the coagulation anomalies developing in streptokinase-treated patients and in others in whom hyperplasminemia ${ }^{1}$ arose spontaneously; to indicate the essential identity of these states; to describe their simulation by in vitro experiment; and to suggest that the coagulation anomaly, developing during hyperplasminemia, may be primarily explained by the concept that fibrinogen, or fibrin proteolysis, or both lead to the production of breakdown products which interfere at the stage of fibrinogen-fibrin conversion. In a fur-

\footnotetext{
1The word "hyperplasminemia" is used to designate a pathological state of enzymatic activity in plasma during which substrates susceptible to plasmin action may be destroyed. As will be apparent from the first section in this communication, hyperplasminemia in vivo is a complex equilibrium state controlled by a number of interrelated and competing reactions.
} 
ther communication (25) we will describe the pathogenesis of a uniquely determined coagulation defect-defective fibrin polymerization-in which a specific inhibitor, derived from the proteolysis of fibrinogen, interferes with the polymerization of fibrin monomer and thus with normal clotting.

The present communication will be divided into six separate but interrelated sections: 1 ) the effects of the hyperplasminemic state in man and its simulation in vitro; 2) the properties of fibrinogen digests prepared by enzymatic digestion; 3) coagulation findings in vivo during hyperplasminemia and in vitro after adding fibrinogen digest to plasma; 4) electrophoretic identification of fibrinogen digest products in plasma; 5) the relation between fibrinogen proteolysis and the coagulation anomaly observed in vivo; and 6) recovery from the effects of hyperplasminemia.

\section{MATERIALS AND METHODS}

\section{Preparations}

Two batches of purified bovine fibrinogen $\left(92^{2}\right.$ and 99 per cent ${ }^{3}$ of the nitrogen being clottable by thrombin) were used. Purified human fibrinogen (91 per cent of the nitrogen being clottable by thrombin) was prepared by the method of Kekwick, Mackay, Nance and Record (26), dissolved in citrate buffer, and stored frozen in small aliquots. Fibrinogen was iodinated with $\mathrm{I}^{131}$ as previously described (20).

Plasminogen was prepared and plasmin obtained by its spontaneous activation in glycerol as previously described (27), or by activation with streptokinase, the plasmin later being rendered activator-free (28). Enzymatic activity was expressed in casein units (29).

Trypsin 4 was a salt-free twice crystallized preparation assaying at 0.25 casein $U$ per $\mu \mathrm{g}$ and soybean trypsin inhibitor (SBTI), 4 a crystalline preparation. Thrombin (Parke-Davis) was dissolved in 50 per cent glycerol solution and stored at $-20^{\circ} \mathrm{C}$. Heparin was a highly purified commercial preparation. ${ }^{5} \epsilon$-Aminocaproic acid was a highly purified, doubly recrystallized preparation. ${ }^{6}$ Streptokinase (SK) was supplied in the form of a highly puri-

\footnotetext{
${ }^{2}$ Kindly supplied as a lyophilized salt-free preparation by Dr. Kent Miller, New York State Department of Health Laboratories, Albany, N. Y.

${ }^{3}$ Kindly supplied by Dr. Birger Blomback, Karolinska Institute, Stockholm, Sweden.

${ }^{4}$ Worthington Biochemical Corporation, Freehold, N. J.

5 Fisher Scientific Company, St. Louis, Mo.

${ }^{6}$ Kindly supplied by Dr. Gilbert Bayne, Merck Sharp and Dohme Research Laboratories, West Point, Pa., and Dr. William Sweeney, Lederle Laboratories Division, American Cyanamid Co., Pearl River, N. Y.
}

fied preparation or as Varidase. ${ }^{7}$ Tosylarginine methyl ester (TAMe) was a crystalline preparation. ${ }^{8}$

Fibrinogen digests were prepared by incubating a 1 per cent solution of fibrinogen (borate buffer $0.1 \mathrm{M}, \mathrm{pH} 8.0$ ) at $25^{\circ} \mathrm{C}$ with plasmin to a final concentration of 2 to 5 casein $\mathrm{U}$ per $\mathrm{ml}$, or trypsin to a final concentration of 2 to 5 casein $\mathrm{U}$ per $\mathrm{ml}$. Every 5 minutes, $0.05 \mathrm{ml}$ of specimen was assayed for its ability to prolong the thrombin clotting time of the test system (vide infra); after a plateau of activity had been attained, residual enzyme was inhibited with SBTI. Aliquots were stable when stored at $-20^{\circ} \mathrm{C}$.

\section{Methods}

Plasma fractionation with ether was performed by the method of Kekwick and Mackay (30), the $F_{1}, F_{2}$, and $\mathrm{F}_{1} \mathrm{~W}$ fractions being isolated. Electrophoretic patterns on these fractions were similar to those reported by the original authors. Plasma fractionation with alcohol (Cohn fractionation) was performed by the method of Lever and co-workers (31). SBTI was added to a final concentration of $0.1 \mathrm{mg}$ per $\mathrm{ml}$ to material subjected to fractionation and to subfractions to prevent proteolysis. SBTI was similarly added to specimens undergoing dialysis prior to electrophoresis.

Boundary (Tiselius) electrophoresis was performed in a Perkin Elmer ${ }^{9} 38 \mathrm{~A}$ apparatus, the $2-\mathrm{ml}$ cell being employed. All runs were made with barbital buffer, 0.1 ionic strength, $\mathrm{pH}$ 8.6. The adequacy of specimen dialysis was checked by conductivity measurements. ${ }^{10}$

One-stage prothrombin times, two-stage prothrombin assays, Factor V (accelerator globulin) assays, antiplasmin assays, plasma plasminogen assays, platelet counts, and the thrombin clotting time were performed as previously described (19). However, where fibrinogen proteolysis mixtures were assayed, the thrombin clotting time was determined in the presence of added plasma [0.05 $\mathrm{ml}$ specimen, $0.05 \mathrm{ml}$ standard bank plasma, $0.3 \mathrm{ml}$ thrombin titration mixture $(32)$, and $0.1 \mathrm{ml}$ thrombin (10 U per $\mathrm{ml})$ ] : the control clotting times were 12 to 14 seconds. Recalcification times were determined in glass tubes using $0.2 \mathrm{ml}$ oxalated plasma (blood centrifuged for 10 minutes at $3,000 \mathrm{rpm}$ ) and $0.2 \mathrm{ml} 0.025 \mathrm{M} \mathrm{CaCl}_{2}$ at $37^{\circ} \mathrm{C}$.

Fibrinogen was estimated by the method of Ratnoff and Menzie (33), modified both by the addition of $0.1 \mathrm{ml} 1$ per cent SBTI to prevent further proteolysis, and a 12hour precipitation period to ensure complete recovery of the precipitate. Results were in agreement with those obtained by an immunological method. ${ }^{11}$ Where plasminogen activator concentration in plasma was known to

${ }^{7}$ Kindly supplied by Dr. James Ruegsegger, Lederle Laboratories, Division of American Cyanamid Company, Pearl River, N. Y.

${ }^{8}$ Mann Laboratories, New York, N. Y.

9 Perkin Elmer Corporation, Norwalk, Conn.

${ }^{10}$ Leeds and Northrop Company, Philadelphia, Pa., conductivity bridge and 2-ml conductivity cell.

11 "Fi test," Hyland Laboratories, Los Angeles, Calif. 


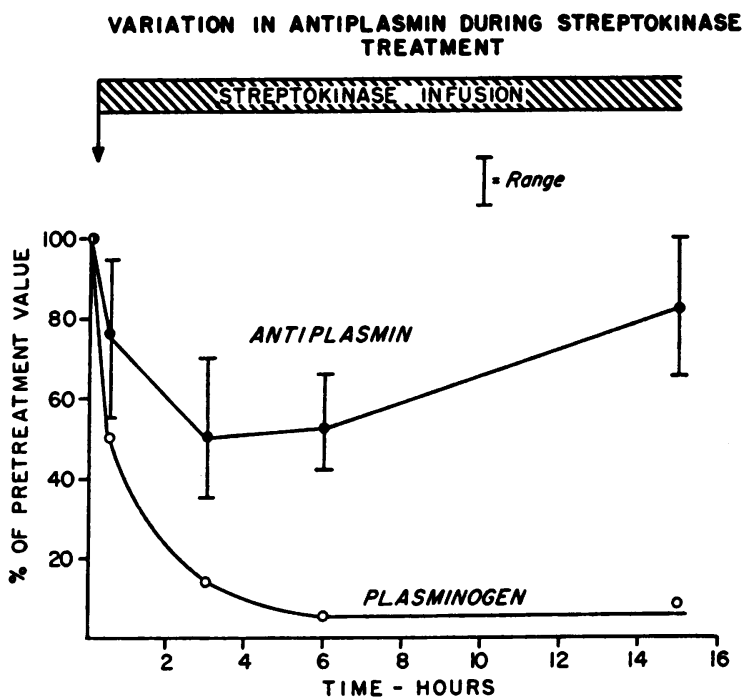

Fig. 1. Plasma concentrations of Plasminogen AND ANTIPLASMIN DETERMINED SERIALLY IN FIVE PATIENTS RECEIVING INTENSIVE SK THERAPY. Values have been expressed as per cent of pretreatment levels and averaged, but the range of antiplasmin determinations is also shown. A substantial excess of antiplasmin was present in the plasma of all patients throughout the course of treatment, despite the fact that complete activation of plasma plasminogen occurred in every case.

be high, $\epsilon$-aminocaproic acid (29) to a final concentration of $0.02 \mathrm{M}$ was used instead of SBTI. With these modifications, fibrinogen added to SK-treated plasmas was quantitatively recovered.

Nonclottable $I^{131}$-labeled fragments. During the proteolysis of $\mathrm{I}^{131}$-fibrinogen, it was expedient to determine the quantity of labeled fragments remaining in the supernatant after clot formation; $0.15 \mathrm{ml}$ specimen, $0.65 \mathrm{ml}$ plasma, and $0.1 \mathrm{ml} \mathrm{SBTI} \mathrm{(10} \mathrm{mg} \mathrm{per} \mathrm{ml}$ ) were clotted by the addition of $0.1 \mathrm{ml}$ thrombin ( $100 \mathrm{U}$ per $\mathrm{ml}$ ). Clots were wound out on wooden applicator sticks and the supernatant left in the cold overnight; any further clots were then removed. Radioactivity in the clots and in the supernatant was determined as previously described (34).

TCA-soluble tyrosine. Aliquots $(0.3 \mathrm{ml})$ of fibrinogen undergoing proteolysis were added to $0.7 \mathrm{ml} 10$ per cent trichloroacetic acid (TCA). The precipitate was washed with 7 per cent TCA and dissolved in $0.5 \mathrm{~N} \mathrm{NaOH}$ and tyrosine determined on supernatant and precipitate with the Folin-Ciocalteau reagent (27).

The method of patient treatment with SK was as previously described and certain of the findings reported here refer to the original group of patients $(19,23)$. Hyperplasminemia developing in association with various disease states was diagnosed by the criteria listed in the Appendix.

The nomenclature of blood clotting factors accepted by the International Committee on Blood Clotting Factors
$(35,36)$ has been followed. Standard statistical methods were employed (37).

\section{RESULTS}

Effects of hyperplasminemia in man and its simulation in vitro

Patients receiving large doses of the plasminogen activator, streptokinase, develop hyperplasminemia because of activation of endogenous plasma plasminogen. Detailed observations on this condition have been reported (19) and attention drawn to its usual self-limiting and transient course.

In vitro assays reveal that whereas plasma plasminogen averages 3 casein $U$ per ml, plasma antiplasmin averages 5 casein inhibitor $U$ per $\mathrm{ml}$ (19). Shown in Figure 1 are assays for plasma antiplasmin made on serial samples drawn from five patients who received SK therapy. The average plasminogen levels are plotted on the figure and antiplasmin values are expressed as percentage of the original starting concentration (mean and range of the observations are shown). At 3 hours, by which time 90 per cent of the plasminogen had been activated, antiplasmin values had fallen to 50 per cent of the original (range, 65 to 35 per cent) ; with continued treatment, even though plasminogen levels slowly fell to zero or near zero levels, antiplasmin levels commenced to rise and by the fifteenth hour were 80 per cent of the starting value (range, 100 to 65 per cent). Noteworthy is the finding that at all times and in all patients uncomplexed antiplasmin was present in substantial amount.

However, despite the presence of excess antiplasmin in the plasma, the patients' plasma fibrinogen fell an average of 25 per cent and all developed a coagulation defect, the average onestage prothrombin time rising from 15 to 24 seconds.

Figure 2 illustrates serial determinations of plasma plasminogen, fibrinogen, and the severity of the coagulation anomaly (measured by prolongation of the thrombin clotting time) following the treatment of plasma with three different concentrations of SK $(20,40$, and 80 SK U per ml plasma).

The two higher concentrations of SK (40 and $80 \mathrm{U}$ per $\mathrm{ml}$ ) caused a more severe coagulation 
defect and a greater fall in plasma fibrinogen and plasminogen than did the lowest concentration (20 SK U per $\mathrm{ml}$ ). However, interesting differences were apparent between the effects of the 40 and 80 SK U per $\mathrm{ml}$ concentrations. Both concentrations effectively reduced plasma plasminogen to zero or near zero levels, but as indicated in the left-hand panel of Figure 2, the speed with which this reduction occurred was different. The slope of initial plasminogen reduction was approximately twice as fast with 80 as with $40 \mathrm{SK}$ $\mathrm{U}$ per $\mathrm{ml}$ and this increased rate of plasminogen activation was associated with a significantly greater and faster fall of plasma fibrinogen. A corresponding increase in the severity of the coagulation anomaly also occurred, and this suggested that fibrinogen proteolysis could be related to the coagulation anomaly.

\section{Enzymatic proteolysis of fibrinogen: Properties of the digestion products}

Plasmin and trypsin degrade fibrinogen so that it becomes totally incoagulable by thrombin. The resulting enzymatic digests, after the addition of a suitable plasmin or trypsin inhibitor, possess novel properties not exhibited by the native fibrinogen. Whereas a solution of native fibrinogen, when added to a plasma or fibrinogen test system, will normally shorten the thrombin clotting time of the mixture, an equivalent quantity of fibrinogen digest will greatly prolong the

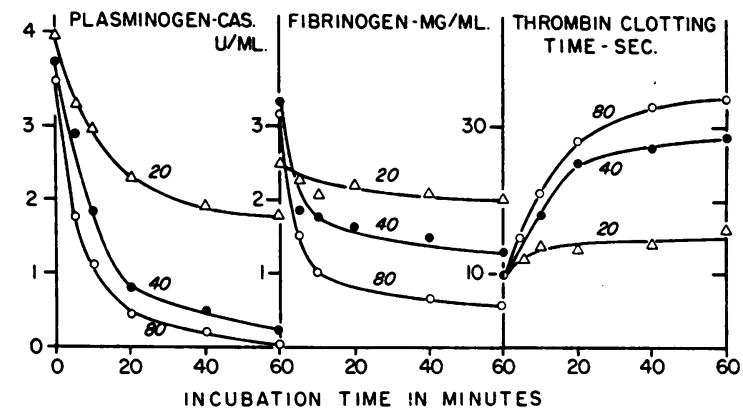

Fig. 2. EFFECT OF ADDING THREE DIFFERENT CONCENtRations of SK $(20,40$, AND 80 U PER ML) to A SINGLE PLASMA. SK concentrations are designated by a superscript number and serial assays for plasminogen (lefthand panel), fibrinogen (middle panel), and thrombin clotting time (right-hand panel) are shown for each concentration.

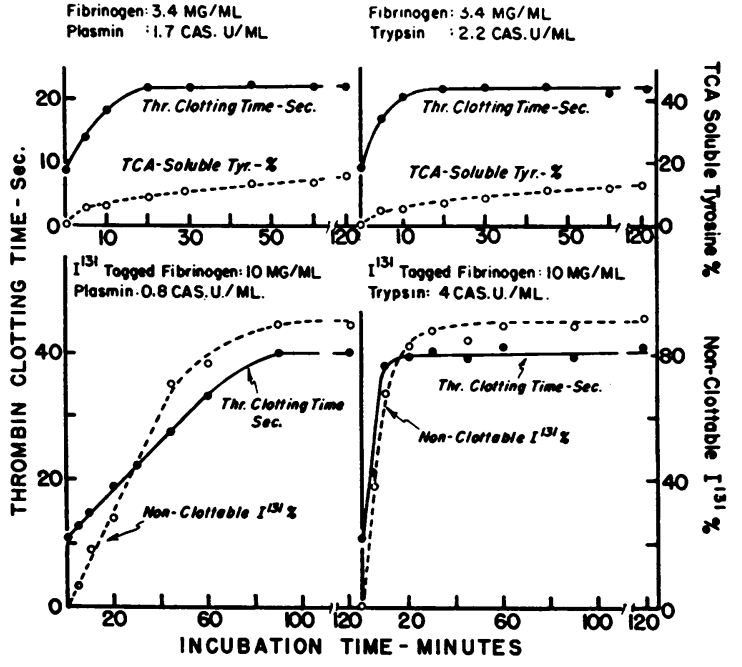

Fig. 3. Fibrinogen proteolysis by two concentraTIONS OF PLASMIN (2 LEFT-HAND PANELS) AND BY TWO CONCENTRATIONS OF TRYPSIN (2 RIGHT-HAND PANELS). Thrombin clotting time (all panels) refers to the ability of the digest to prolong the thrombin clotting time of the standard assay system. This parameter is correlated with the development of TCA-soluble tyrosine (above), and using $\mathrm{I}^{131}$-labeled fibrinogen with the formation of nonclottable $\mathrm{I}^{131}$-labeled fragments (below).

thrombin clotting time of the mixture. ${ }^{12}$ Indeed, under suitable experimental conditions, the thrombin clotting time of the mixture may be prolonged to infinity.

Figure 3 illustrates serial findings, especially with relation to the development of "antithrombin" activity, occurring during the enzymatic proteolysis of $\mathrm{I}^{131}$-labeled fibrinogen by plasmin or trypsin. The original concentration of fibrinogen was $3.4 \mathrm{mg}$ per $\mathrm{ml}$ in the two top sections of the diagram and $10 \mathrm{mg}$ per $\mathrm{ml}$ in the two bottom sections; the left-hand sections illustrate experiments with two concentrations of plasmin and the

\footnotetext{
12 Conventional usage would suggest that the term "antithrombic activity" should be applied to designate the property of fibrinogen digestion products in prolonging the thrombin clotting time of normal plasma. Similarly it would be customary to state that during the digestion process an "antithrombin" was formed. This nomenclature is clearly unsatisfactory, for its use implies that a specific mechanism of inhibition has been demonstrated where such is not the case. Nevertheless, because other suitable terms are lacking, the words "antithrombin" and "antithrombic activity" will be used sparingly in this communication, solely for descriptive convenience and without any implications as to the mechanisms of action.
} 


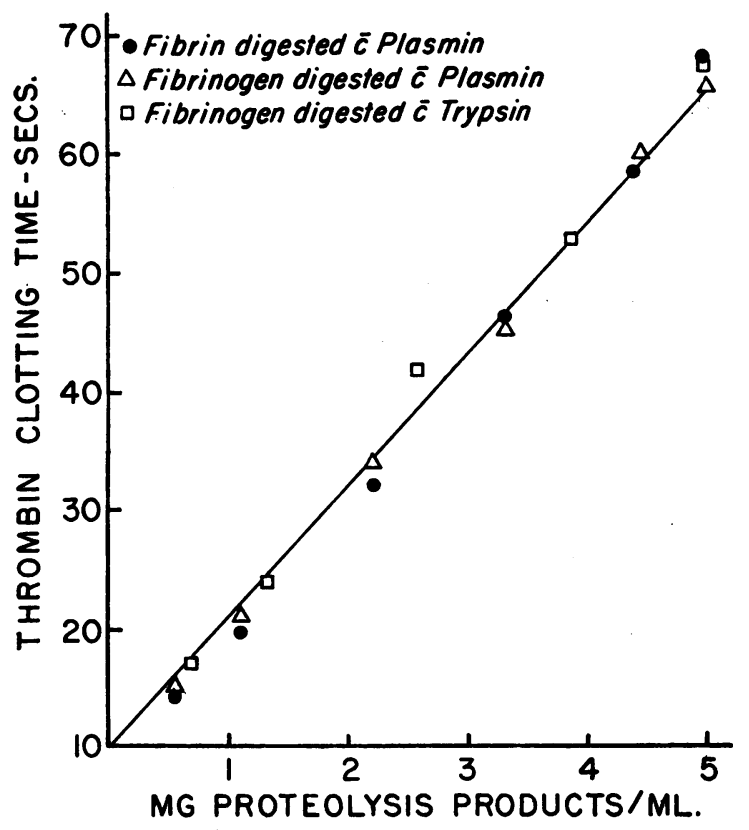

Fig. 4. INHIBITION OF CLOTTING BY PROTEOLYTIC PRODUCTS. The property of fibrinogen or fibrin digests to inhibit clotting of the standard assay system (thrombin clotting time, ordinate) was a function of the concentration of proteolysis products (abscissa) and independent of its source, fibrin or fibrinogen, or the enzyme employed, trypsin or plasmin.

right-hand ones those with two different concentrations of trypsin.

The upper two graphs show that plasmin and trypsin, employed in approximately equivalent proteolytic concentrations, degrade fibrinogen in a virtually indistinguishable manner. ${ }^{13}$ In both instances the ability of the digest solution to prolong the thrombin clotting time of the assay system ("antithrombin" action) increased similarly to an equal peak and thereafter remained stable, even though test of residual enzymatic activity at the end of the experimental period of 2 hours showed in both instances less than 20 per cent enzymatic decay. Of additional significance is the fact that although the digest "antithrombin" activity stabilized early in the experiment, further digestion, as evinced by a small but steady rise

13 Purified fibrinogen preparations are invariably contaminated with plasminogen. Consequently, the similarity between the actions of trypsin and plasmin on fibrinogen might result not only from the specific enzymatic actions of trypsin on fibrinogen, but also because this enzyme is a plasminogen activator. of TCA-soluble tyrosine, continued throughout the experiment.

The two lower graphs illustrate different experimental conditions, for in this instance tryptic activity was relatively five times as great as plasmin activity: "antithrombin" activity of the plasmin digest rose more slowly than that of the tryptic digest, but the final recorded activities were equal. The other parameter measured in these experiments was the nonclottable $\mathrm{I}^{131}$. This determination (see Methods) involved mixing an aliquot of digest (to which an enzyme inhibitor had been added) with plasma, clotting the mixture with thrombin, and determining the amount of supernatant radioactivity. The lower two graphs show that the nonclottable $\mathrm{I}^{131}$ assay paralleled, in both experiments, the rise of "antithrombin" activity. However, in neither instance was more than 90 per cent of the $I^{131}$ detected in the supernatant.

It may be inferred from Figure 3 that trypsin and plasmin exert quantitatively similar actions on fibrinogen, at least as far as the ability of both species of proteolysis products to prolong the thrombin clotting time of the assay system is concerned. The validity of this inference is confirmed by Figure 4, which illustrates the prolongation of the thrombin clotting time of the

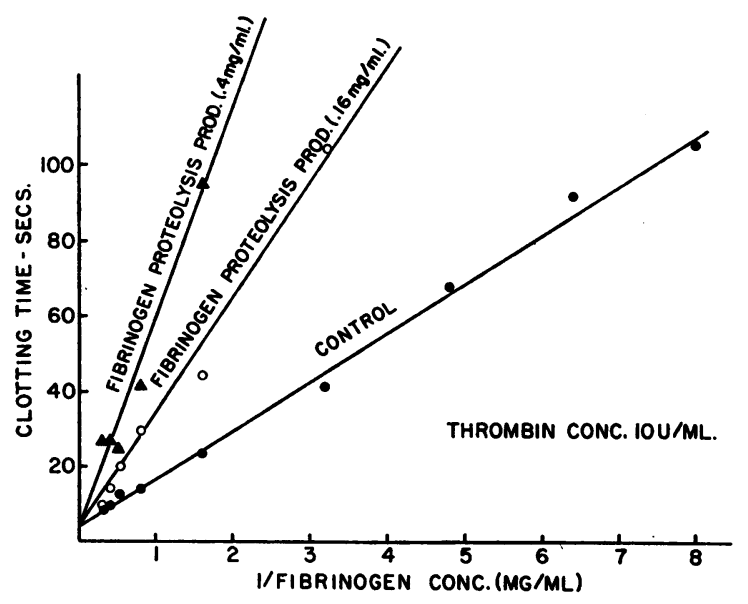

Fig. 5. INFLUENCE OF FIBRINOGEN CONCENTRATION (1/FIBRINOGEN CONCENTRATION, ABSCISSA) ON CLOTTING TIME (1/REACTION VELOCITY, ORDINATE), USING A SINGLE THROMBIN CONCENTRATION AND TWO DIFFERENT CONCENTRATIONS OF FIBRINOGEN PROTEOLYSIS PRODUCTS. This data, analogous to a Lineweaver-Burk plot, suggests that fibrinogen proteolysis products interfere competitively at some stage of fibrinogen-fibrin conversion. 


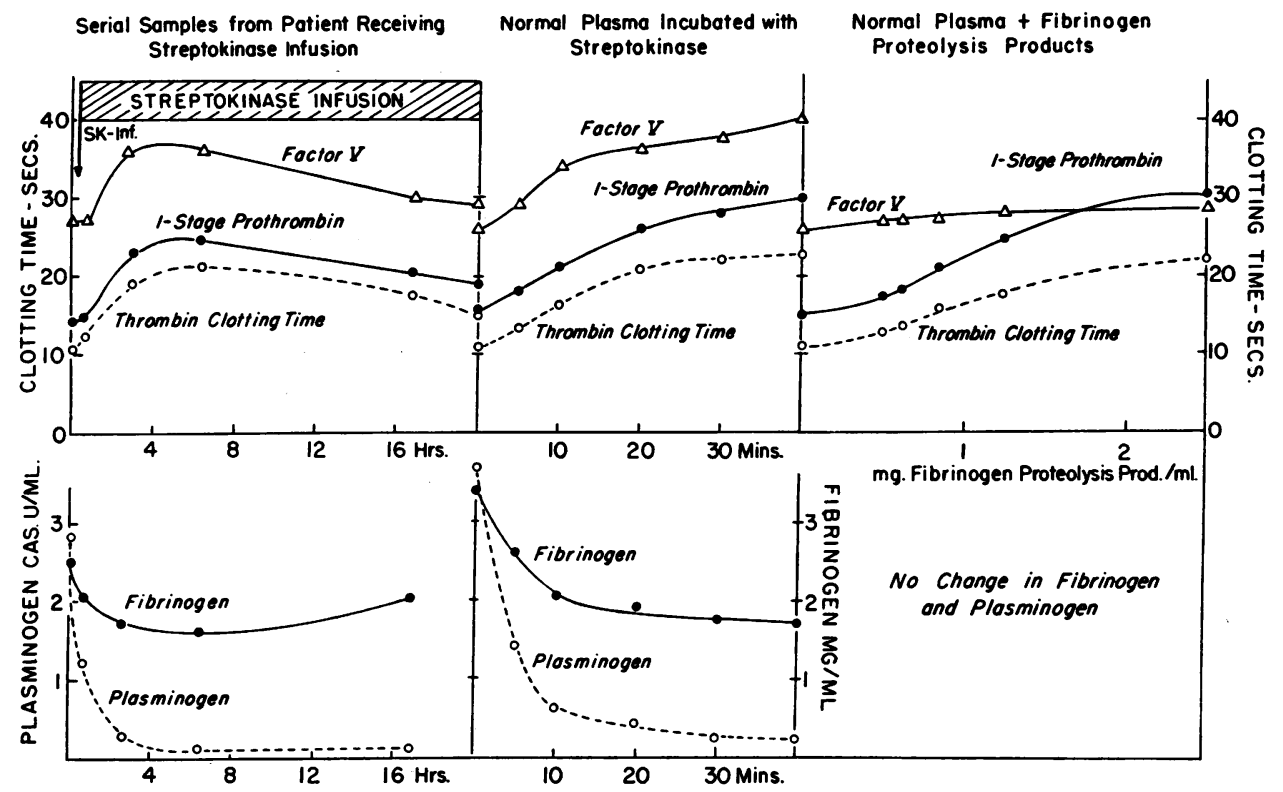

Fig. 6. Coagulation anomalies occurring in a patient who received SK therapy (LEFT-HAND PANEL), IN A PLASMA TO WHICH STREPTOKINASE HAD BEEN ADDED (MIDDLE PANEL), AND IN A PLASMa TO WHICH INCREMENTAL ADDITIONS OF FIBRINOGEN PROTEOLYSIS PRODUCTS WERE MADE (RIGHT-HAND PANEL). Ordinate values are similar throughout, but the abscissal scales are different: at the left, the scale is time in hours; in the middle, time in minutes; and on the right, concentration of fibrinogen proteolysis products. The general similarity (see text) between the coagulation findings recorded in each panel is evident.

assay system as a function of the concentration of plasmin or trypsin proteolysis products. Prolongation of thrombin clotting time in the assay system was influenced solely by the concentration of proteolysis products and was independent of the enzyme employed.

The data displayed in Figure 4 also demonstrate that fibrin may be substituted for fibrinogen as the source of proteolysis products without quantitative disturbance in the yield of "antithrombin." The experiment was conducted by clotting an aliquot of fibrinogen with a small quantity of thrombin prior to enzymatic digestion, and comparing the effect of this digest to that of a control fibrinogen aliquot. The yields of "antithrombin" were similar in every case.

Figure 5 shows the effect on the thrombin clotting time of adding two separate concentrations of fibrinogen proteolysis products to varying concentrations of fibrinogen. The graph is plotted in Lineweaver-Burk form; the abscissa is the reciprocal of the fibrinogen concentration and the ordinate is clotting time in seconds (a reciprocal of reaction velocity). The control and fibrinogen proteolysis product assay lines intercept on the ordinate, suggesting that fibrinogen proteolysis products "competitively" inhibit at one or more stages of the over-all reaction of fibrinogen-fibrin conversion by thrombin.

\section{The coagulation defect arising in patients and its in vitro simulation}

Figure 6 (left-hand portion) shows serial coagulation assays on a patient receiving streptokinase therapy. Maximum abnormalities in the one-stage prothrombin test, thrombin clotting time, fall of Factor $\mathrm{V}$ activity, and fall in fibrinogen occurred after 4 hours' treatment, at which time plasminogen levels were zero or near zero. Despite the continuance of therapy, the coagulation abnormalities showed steady improvement during the next 16 hours, by which time the plasma fibrinogen had risen to normal levels. This patient exhibited no clinical evidence of a hemorrhagic diathesis. Occasionally, under these circumstances (19) severe coagulation abnormali- 


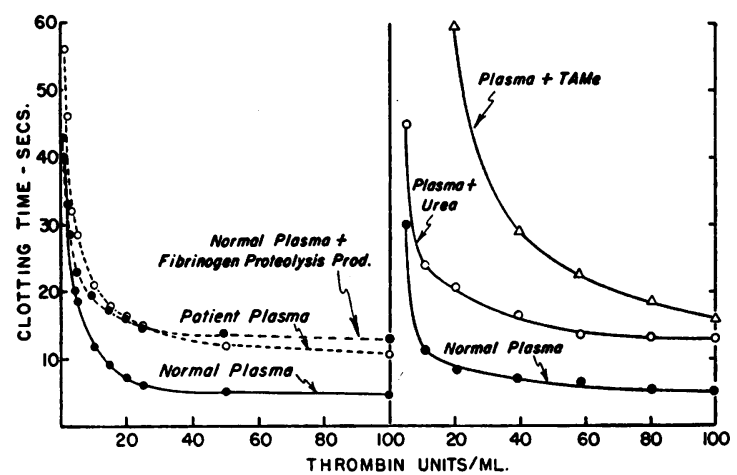

Fig. 7. Thrombin clotting time (ORdinate) AS A FUNCTION OF THROMBIN CONCENTRATION (ABSCISSA). The left-hand panel shows normal plasma, plasma from a patient with hyperplasminemia, and a plasma containing fibrinogen proteolysis products $(1.8 \mathrm{mg}$ per $\mathrm{ml})$. The right-hand panel shows normal plasma, plasma containing urea (120 mg per $\mathrm{ml}$ ), and plasma containing TAMe (5 $\mathrm{mg}$ per $\mathrm{ml})$. With the exception of the TAMe-containing plasma, the difference in thrombin clotting time between the normal and abnormal plasmas was unaltered by increase of thrombin concentration.

ties may be produced and a clinically important hemorrhagic diathesis may result.

The middle portion of Figure 6 illustrates serial coagulation assays made on a plasma specimen to which SK had been added in vitro. The time scale in this instance is in minutes as compared to the time scale of hours as shown on the left. The middle section illustrates a more profound degree of hyperplasminemia as plasminogen activation was faster, the fall of fibrinogen was greater, and the respective changes in the onestage prothrombin test, the thrombin clotting time, and the fall of Factor $\mathrm{V}$ activity were somewhat greater. Since this was an in vitro test system, the coagulation defect ultimately stabilized and there was no recovery phase. Despite these differences, attendant upon the use of a different experimental model, the changes between the left and middle portions of Figure 6 show remarkable qualitative similarities.

The right-hand portion of the diagram illustrates the effects of adding increments of fibrinogen digest (prepared by plasmin digestion of fibrinogen with subsequent inhibition of plasmin) to normal plasma. Noteworthy is the fact that the rise of one-stage prothrombin and thrombin clotting times was roughly proportional to the quantity of added digest; but since free enzyme was lacking, assays for Factor $\mathrm{V}$ activity were unaltered. In all three diagrams the rise of onestage prothrombin time essentially paralleled the prolongation of the thrombin clotting time, a correlation established as highly significant in a large series of patients treated with SK (19). The essential similarity of the coagulation findings in these three experiments in which fibrinogen, either digested in plasma in vivo, in vitro, or predigested and then added to plasma, suggested that fibrinogen proteolysis might underlie the main coagulation anomaly, although it would not account for the findings with respect to fall in Factor $\mathrm{V}$ concentration.

The left-hand portion of Figure 7 shows thrombin clotting times as a function of thrombin concentration for normal plasma, plasma from a patient with hyperplasminemia of "spontaneous" origin occurring during the course of leukemia, and plasma containing fibrinogen proteolysis products. The three curves over the greater and relevant part of the experiment remain essentially parallel and distant from one another; particularly significant is the finding that over the higher range of thrombin concentrations the individual plasma determinations were not only parallel to one another but also to the abscissa (plasma from SK-treated patients, not illustrated, showed similar characteristics). The right-hand portion of the figure illustrates a similar experiment in which normal plasma, plasma containing urea [an in-

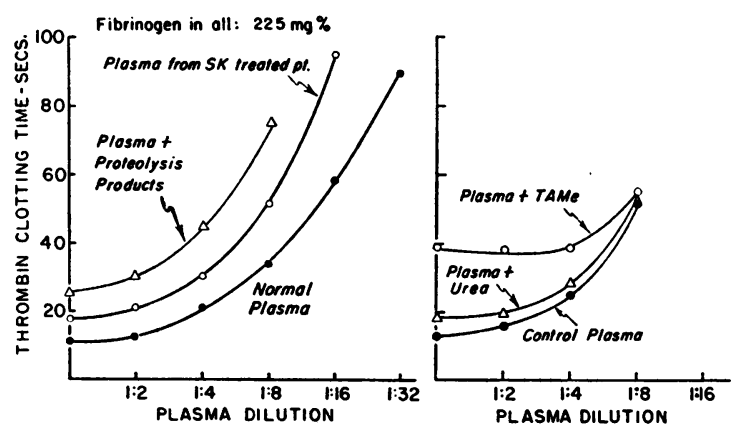

Fig. 8. Thrombin clotting time (ordinate) as a FUNCTION OF PLASMa dilution (ABSCISSA). The lefthand panel shows a normal plasma, that from a SKtreated patient, and plasma containing fibrinogen proteolysis products $(1.9 \mathrm{mg}$ per $\mathrm{ml})$. The right-hand panel shows a normal plasma, plasma plus urea $(60 \mathrm{mg}$ per $\mathrm{ml}$ ), and plasma plus TAMe ( $2 \mathrm{mg}$ per $\mathrm{ml})$. With the exception of the TAMe-containing plasma, all showed a similar relationship of thrombin clotting time to dilution. 


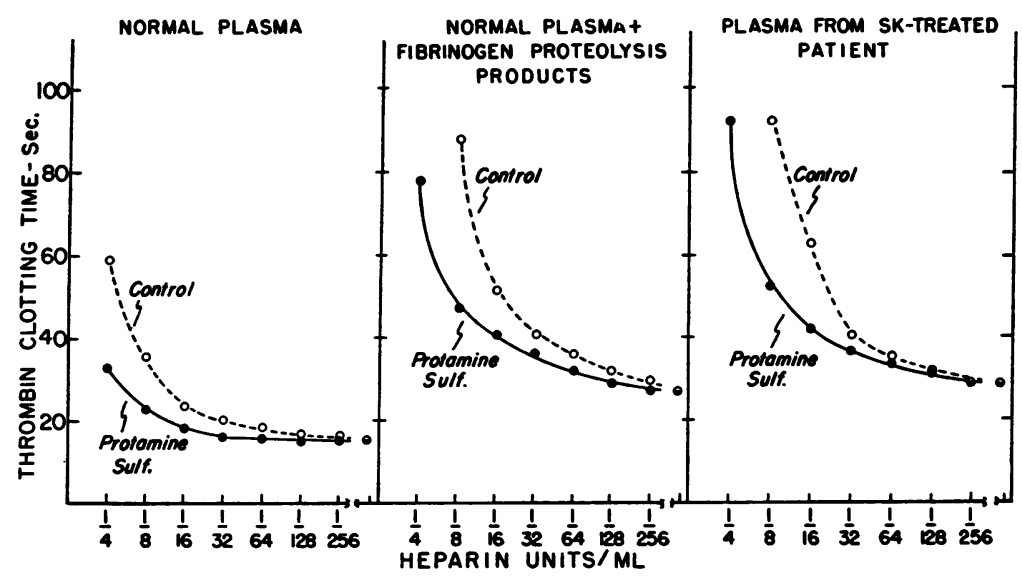

Fig. 9. HEPARIN TOLERANCE ASSAYS ON NORMAL PLASMa (LEFT-HAND PANEL), NORMAL PLASMa PLUS FIBRINOGEN PROTEOLYSIS PRODUCTS (MIDDle panel), aNd plasma from a SK-treated patient (Right-hand panel). There is a marked similarity between the findings recorded for the abnormal plasmas in the middle and right-hand panels. The results indicate that, although the effects of heparin and fibrinogen proteolysis products or SK treatment are additive, protamine sulfate corrects only the heparin defect.

hibitor of fibrin polymerization (38) ], and plasma with TAMe [a thrombin inhibitor (39)] were used. The normal and urea-containing plasma curves exhibit the same relationship to each other as do the normal and abnormal curves in the lefthand portion of the figure, but the TAMe plasma does not; the latter curve is of a different shape and the thrombin clotting time anomaly is partially corrected by high thrombin concentrations.

The left-hand portion of Figure 8 shows thrombin clotting time as a function of plasma concentration for a normal plasma, plasma from a SKtreated patient, and plasma containing fibrinogen proteolysis products. These three dilution curves are of similar shape, but are significantly separated throughout their course (plasma from a patient with spontaneous hyperplasminemia, not illustrated, showed similar characteristics). The right-hand portion of the figure illustrates an identical experiment with normal plasma, ureacontaining plasma, and TAMe plasma; the urea plasma exhibits an equivalent dilution curve to the plasmas shown in the left-hand section of the figure, but the TAMe-containing plasma demonstrates dissimilar characteristics.

Figure 9 illustrates heparin tolerance curves on normal plasma, normal plasma with fibrinogen breakdown products, and plasma from a SKtreated patient. In each instance the effect of neutralizing heparin action with protamine sulfate is also shown. The abnormal plasmas (shown in the middle and right sections of the diagram) differ from the normal plasma (shown on the left) inasmuch as, at first sight, they appear to have a much smaller tolerance for heparin. Nevertheless, after neutralization with protamine sulfate, the protamine sulfate and control curves

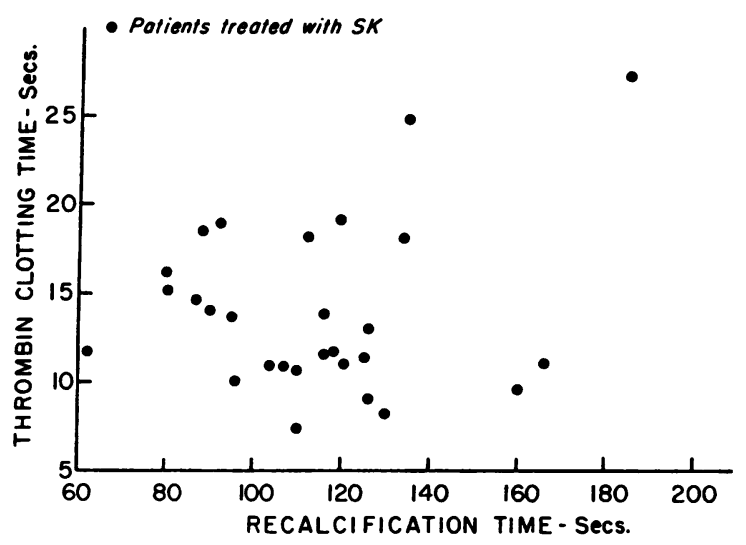

Fig. 10. Recalcification times (ABScissa) IN PLASMA FROM SK-treated PATIENTS PLOTTED AGAINST THROMBIN CLOTTING TIMES (ORDINATE). Although many of the patients' plasmas demonstrated evidence of a coagulation anomaly (thrombin clotting time $>12$ seconds), only three showed prolonged recalcification times $(>140$ seconds), and evidence of correlation between these parameters was lacking $(p>0.1)$. 


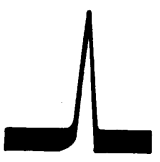

FIBRINOGEN $2.15 \times 10^{-5}$

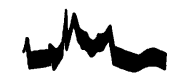

COHN FRACTION $1+3$

Normal Plosmo

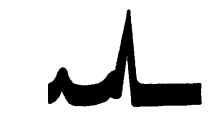

KEKWICK F, FRACTION

Normal Plosmo

$2.20 \times 10^{-5}$

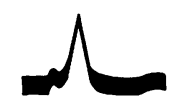

FIBRINOGEN (Spont. Proteolysis) $2.16 \times 10^{-5}$ ond $2.82 \times 10^{-5}$

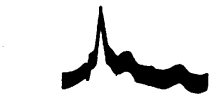

COHN FRACTION $1+3$ SK-Treated Plasma

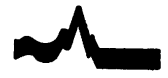

KEKWICK F, FRACTION

SK-Treated Plasma

$2.05 \times 10^{-5}$
$2.55 \times 10^{-5}$

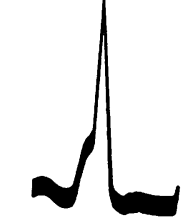

FIBRINOGEN (Plasmin Proteolysis) $2.10 \times 10^{-5}$ and

$2.85 \times 10^{-5}$

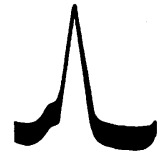

FIBRINOGEN (Trypsin Proteolysis) $2.20 \times 10^{-5} 2.57 \times 10^{-5}$

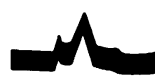

KEKWICK $F_{\text {I }}$ FRACTION Patient Plasma with Coagulation Defect $2.19 \times 10^{-5} \quad 2.95 \times 10^{-5}$

Fig. 11. Electrophoretic PATterns OF Fibrinogen, Fibrinogen digests, AND PLASMa fRactions. Descending limb patterns only are shown, and direction of migration is from right to left. Mobilities expressed as $\mathrm{cm}^{2} /$ volt$\sec \times 10^{-5}$ and the scale reduction has been uniform. For detailed description see text.

exhibit precisely the same relationship in each separate panel of the diagram, indicating that neither in the plasma containing exogenously added fibrinogen proteolysis products nor in that from the patient does protamine sulfate correct the coagulation anomaly.

The relationship of thrombin clotting time to recalcification time in patients receiving SK therapy is shown in Figure 10. Serial observations (12 patients, 32 observations) revealed no consistent patterns with respect to recalcification times, and the majority of the observations fell within the normal range. Moreover, as is evident from the figure, there was not only a complete lack of correlation between these parameters, but a marked increase of the thrombin clotting time was frequently associated with a normal recalcification time.
Electrophoretic identification of fibrinogen digest products in purified solution and in plasma

Enzymatic digestion of fibrinogen by trypsin ${ }^{13}$ or plasmin produces characteristic alterations in the electrophoretic pattern examined by boundary (Tiselius) electrophoresis, characteristics that may, under restricted circumstances, be used for the identification of the digestion products.

Figure 11 illustrates representative electrophoretic patterns of fibrinogen subjected to enzymatic digestion. Similar patterns were observed in both limbs of the cell, but for the sake of simplicity, only descending limb patterns are shown in Figure 11. On the left is seen the electrophoretic pattern of native fibrinogen, and successively, the patterns obtained after this fibrinogen had become totally incoagulable after its spontaneous breakdown or its treatment with plasmin 
or trypsin. The three degraded fibrinogen patterns show essentially similar changes, since, although the experimental conditions were different, the final patterns may all represent the results of plasmin ${ }^{14}$ action on fibrinogen.

Compared with the control pattern, the three patterns of degraded fibrinogen show a main peak of mobility similar to that of the original fibrinogen and a second ill defined peak of greater mobility. Clearly, the second peak is not electrophoretically homogenous, but its presence serves to identify fibrinogen proteolysis products. Trace components with mobilities of 4.0 to $5.0 \mathrm{~cm}^{2}$ per volt-sec $\times 10^{-5}$ were also detected in some patterns, but their presence was inconstant and their quantity small so that they could not be clearly distinguished from other plasma components carried down in the fractionation process.

The significance of these observations for the identification of fibrinogen proteolysis products contained either in plasma or in purified systems is supported by other electrophoretic data. Fibrinogen, either in the purified state or separated from plasma $\left[F_{1}\right.$ fraction, Kekwick ether method $^{15}(30)$ ], gives a sharp peak with a mobility of $2.15 \pm 0.05 \mathrm{~cm}^{2}$ per volt-sec $\times 10^{-5}$ (range of 20 determinations, 2.11 to 2.26 ). However, samples containing fibrinogen proteolysis products in addition to fibrinogen (also separated by the Kekwick ether method) showed one peak with a mobility of $2.18 \pm 0.08 \mathrm{~cm}^{2}$ per volt-sec $\times 10^{-5}$ (range of 23 samples, 2.10 to 2.28 ) and a second with a mobility of $2.88 \pm 0.22$ (range of 23 samples, 2.69 to 3.40 ). Trace components with a higher mobility (vide supra) were not used for identification purposes.

14 It is generally accepted that spontaneous fibrinogenolysis occurs because contaminating plasminogen undergoes spontaneous activation. Similarly as we have indicated in footnote 13 , it is possible that, under the present experimental conditions, the activator action of trypsin on contaminating plasminogen may be significant in determining the ultimate pattern of fibrinogen digestion.

${ }_{15}$ Although the $F_{1}$ only contains 50 per cent nitrogen clottable by thrombin, electrophoretic visualization of the fibrinogen peak and the area around it is excellent since the main contaminant is albumin, which migrates well clear of the field under study. Consequently, the $F_{1}$ fraction was routinely used for electrophoresis, and examination of the $F_{1} W$ fraction ( 80 per cent of the nitrogen clottable by thrombin) was only used to check results.
Electrophoretic examination of whole plasma before and after the addition of sufficient SK to produce a coagulation defect revealed only that the fibrinogen peak was diminished. Accordingly electrophoretic studies were made on various plasma fractions and these also are illustrated in Figure 11. A plasma sample, to which SK had been added, was fractionated by the Cohn procedure after the thrombin clotting time had risen from 10.1 to 18 seconds. Cohn fraction $1+3$ of the SK-treated plasma showed the anomalies characteristic of fibrinogen proteolysis when compared with Cohn fraction $1+3$ from the untreated plasma. Furthermore this fraction of SK-treated plasma prolonged the thrombin clotting time of the plasma test system to 15.2 seconds, whereas the thrombin clotting time of the test system with the fraction from the untreated plasma added was 10.3 seconds. The other Cohn fractions from the SK-treated plasma did not prolong the thrombin clotting time of the assay system.

Similarly, fractionation of paired samples by the Kekwick ether method and examination of the respective $F_{1}$ fractions, revealed that the samples from SK-treated plasma showed not only the electrophoretic stigmata of fibrinogen proteolysis products, but also prolonged the thrombin clotting time of the assay systems. Shown in Figure 11 (bottom line) are the $F_{1}$ electrophoretic patterns from a control plasma, a SK-treated plasma and a plasma from a patient who developed hyperplasminemia during his terminal illness due to lymphatic leukemia. In both hyperplasminemic plasmas the $F_{1}$ fibrinogen peak is reduced in size and deformed in its advancing limb because of admixture with faster moving components; in both instances the $F_{1}$ fraction prolonged the thrombin clotting time of the assay systems.

Electrophoretic methods for demonstrating the presence of fibrinogen digest products in plasma proved to be qualitative rather than quantitative, since a portion of the product present could not be distinguished electrophoretically from fibrinogen, and considerable loss of digest product occurred in the fractionation step preliminary to electrophoretic examination. This loss, which appeared to be of the order of 50 per cent, could not be precisely quantitated, because the coagula- 

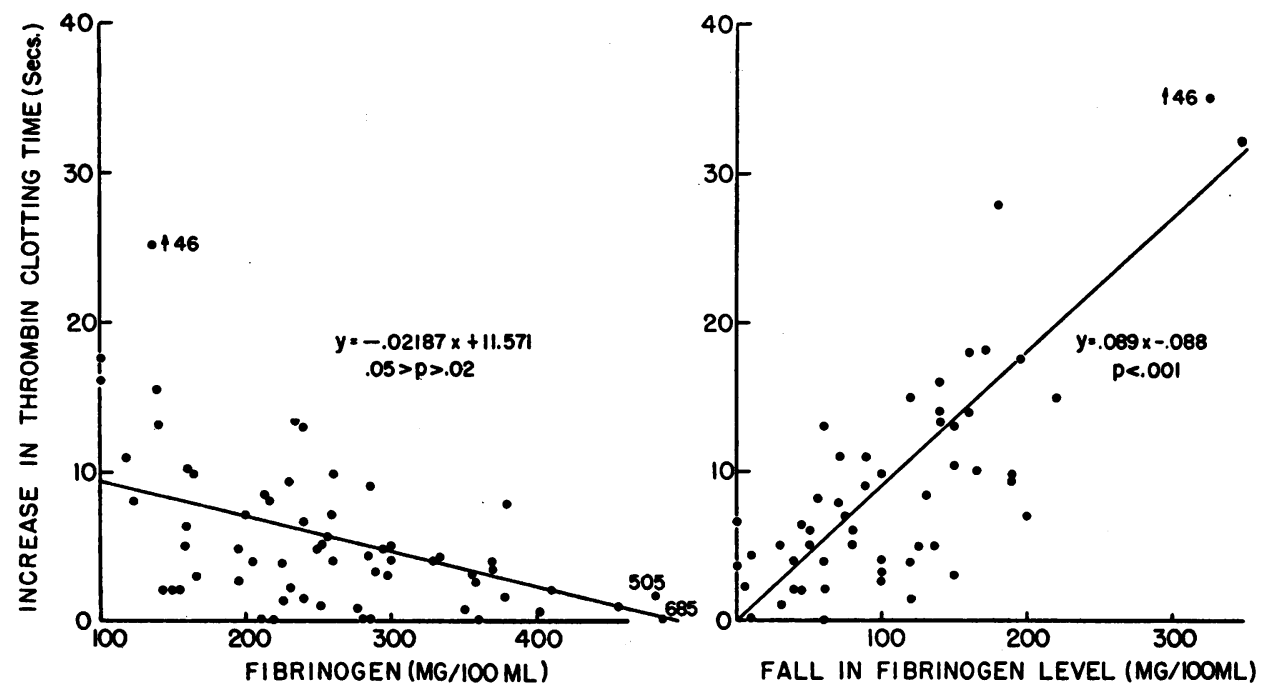

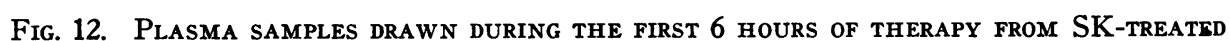
PATIENTS. In both panels the ordinate is increase of thrombin clotting time (thrombin clotting time minus pretreatment values); in the left-hand panel the abscissa is plasma fibrinogen concentration, and in the right-hand panel fall of fibrinogen (pretreatment values minus plasma fibrinogen). The parameters in the right-hand panel, increase of thrombin clotting time and fall of fibrinogen, are highly correlated $(p<0.001)$; this finding accounts for the low value of inverse correlation $(0.05>p>0.02)$ displayed in the left-hand panel between increase of thrombin time and plasma fibrinogen.

tion test system ${ }^{16}$ was influenced by factors other than the quantity of added fibrinogen digest product. Nevertheless, the method afforded a demonstration of the presence of an abnormal molecular species in plasma exhibiting the coagulation anomaly. Moreover, the electrophoretic patterns showed this entity to have the stigmata of fibrinogen digest products, and the fractionated samples inhibited the coagulation assay system in the predicted manner.

Fibrinogenolysis and the coagulation anomaly observed in streptokinase-treated patients

The contention that fibrinogen proteolysis secondary to hyperplasminemia causes a specific coagulation anomaly, due not to the development of hypofibrinogenemia but to the presence in plasma of fibrinogen proteolysis products, requires the support of clinical evidence. Such evidence has

\footnotetext{
16 Although other fractions prepared by the Kekwick procedure had no detectable action in prolonging the thrombin clotting time of the assay system, some inhibition was noted with the supernatant from the $F_{1}$ procedure, although this effect was relatively small. Incomplete precipitation of the fibrinogen breakdown products was believed responsible.
}

been gathered in patients receiving SK therapy for acute thromboembolic vascular disease.

Patients receiving intensive SK therapy develop a coagulation defect that is usually maximal in degree during the first 6 hours of treatment; for this reason the data shown in Figure 12 were obtained during this period (62 observations on 29 patients). The increase of thrombin clotting time over pretreatment levels, the parameter $(24$, 25) that best serves to measure the severity of the defect, is plotted on the ordinate of both panels in Figure 12. On the left, increase of thrombin clotting time is plotted against the plasma fibrinogen level and on the right against the fall of plasma fibrinogen (control pretreatment concentration minus actual plasma fibrinogen at time of sampling). Correlation coefficients have been calculated for both sets of data and regression lines fitted.

Inspection of the data in the left-hand panel of Figure 12 shows that the severity of the coagulation defect was frequently unrelated to the development of hypofibrinogenemia, as the severe form was sometimes seen when plasma fibrinogen levels were in the normal range. However, a 
low but statistically significant degree of correlation $(0.05>p>0.02)$ existed between fibrinogen concentration and increase of thrombin clotting time. The low value for the correlation coefficient and the slope of the regression line ${ }^{17}$ suggested that the apparent relationship between these parameters was secondary rather than primary. The right half of Figure 12 illustrates the increase of thrombin clotting time plotted against the fall of fibrinogen. These observations were correlated in a highly significant manner ( $\mathrm{p}$ $<0.001)$ and suggested that the degree of coagulation anomaly was related to the extent of fibrinogen proteolysis.

Interpretation of the highly significant inverse correlation coefficient (and the corresponding regression equation) demonstrated to exist, by in

1i The regression equation indicates that for every 100 $\mathrm{mg}$ per $100 \mathrm{ml}$ reduction in plasma fibrinogen concentration the thrombin clotting time changes only 3 seconds, a calculated figure at such obvious variance with the recorded data that the apparent relationship between increase in thrombin clotting time and hypofibrinogenemia is unlikely to be a primary one.

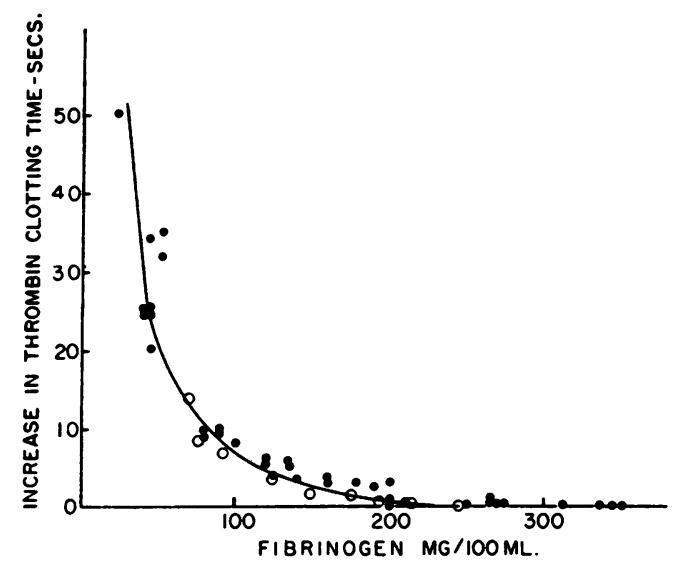

vivo investigation, between increase of thrombin clotting time and fall of plasma fibrinogen (righthand portion of Figure 12) involves consideration of comparable in vitro findings. Such in vitro data is shown in Figure 13. Increase of thrombin clotting time is plotted on both ordinates of Figure 13 ; the left-hand panel shows this parameter plotted against the fibrinogen concentrations of progressively diluted plasma and on the righthand side plotted against concentrations of fibrinogen proteolysis products added to two plasma test systems.

Plasma dilution caused only a minor increase of the thrombin clotting time (left side of Figure 13) until a critical concentration of 100 to 150 $\mathrm{mg}$ fibrinogen per $100 \mathrm{ml}$ was reached; thereafter a rapid increase of thrombin clotting time occurred with further dilution. These findings with respect to dependence of thrombin clotting time on plasma fibrinogen concentration are comparable to the in vivo data shown in the left-hand panel of Figure 12, although here actual plasma fibrinogen values below $100 \mathrm{mg}$ per $100 \mathrm{ml}$ were not encountered.

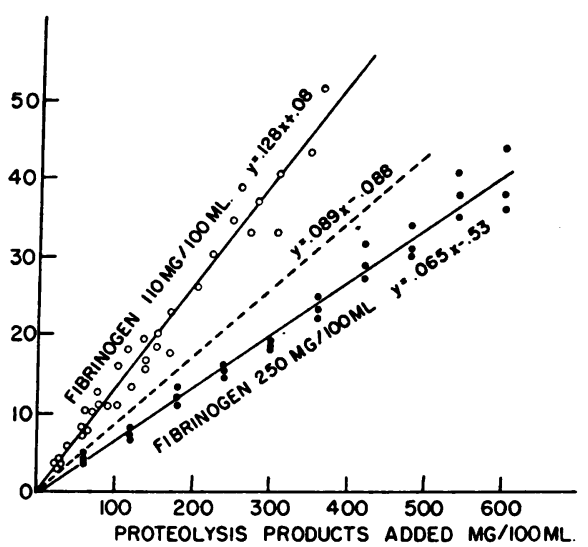

Fig. 13. INFLUENCE OF FIBRINOGEN CONCENTRATION AND FIBRINOGEN PROTEOLYSIS PRODUCTS oN THE PLASMa thrombin CLOTTING time. The left-hand panel shows the effect on the thrombin clotting time (ordinate) of plasma dilution expressed in terms of fibrinogen concentration (abscissa); little change occurs in this parameter until the plasma fibrinogen concentration is reduced to 100 to $150 \mathrm{mg}$ per $100 \mathrm{ml}$. (Open circles, plasma diluted with serum: solid dots. plasma diluted with saline.) The right-hand panel displays, on the ordinate, the increase of thrombin clotting time resulting from the addition of fibrinogen proteolysis products (concentration on abscissa) to plasmas containing, respectively, 110 and $250 \mathrm{mg}$ fibrinogen per $100 \mathrm{ml}$. Increasing fibrinogen proteolysis product concentration induced a linear increase of thrombin clotting time, but the slopes of the increase were markedly different, being less with the higher fibrinogen concentration. Since the in vitro plasma fibrinogen concentrations were similar to those determined $i v$ vivo (Figure 12), the regression line for the patient data is plotted (stippled line) on the panel. It falls in an intermediate position between the two series of in vitro determinations. 


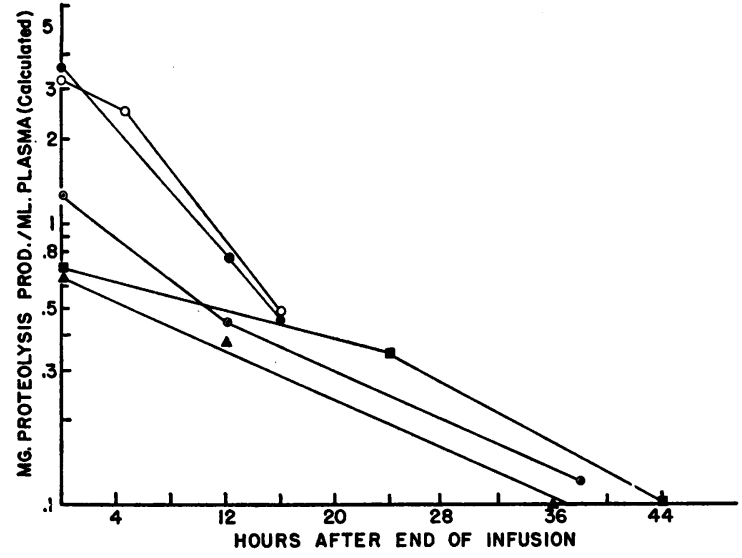

Fig. 14. Plasma clearance rates of fibrinogen proteolysis pROdUCtS IN SK-treated patients. The ordinate is milligrams of proteolysis products per ml plasma (exponential scale, calculated) and the abscissa is time in hours after the termination of therapy. Two patients, who developed the severest coagulation defect and whose treatment was stopped on this account, showed 50 per cent plasma clearance rates approximately double those of the other three patients illustrated and of an additional six also studied.

The right-hand portion of Figure 13 illustrates in vitro experiments comparable to the in vivo findings recorded in the right-hand portion of Figure 12.

Since the influence of fibrinogen proteolysis products on coagulation is dependent upon the ratio of proteolysis products to fibrinogen in the test system (Figure 5), the results of adding these products to two different plasma test systems, the one containing 110 and the other $250 \mathrm{mg}$ fibrinogen per $100 \mathrm{ml}$, are shown in Figure 13. Increments of fibrinogen proteolysis products are expressed as milligrams of proteolysis products per $100 \mathrm{ml}$ added to the test system. The values of 110 and $250 \mathrm{mg}$ fibrinogen per $100 \mathrm{ml}$ plasma were chosen to simulate the lowest and the average plasma fibrinogen concentrations recorded in the patients (Figure 12). Figure 13 shows that the increase of thrombin clotting time was linearly related to increase of fibrinogen proteolysis product concentration in both plasma test systems, but, as would be expected, the regression slope was substantially steeper in the plasma system containing the lesser fibrinogen concentration as compared with that containing the greater.

Since the majority of plasma fibrinogen values, recorded in Figure 12, lay within the range of 100 to $300 \mathrm{mg}$ per $100 \mathrm{ml}$, the in vitro data of Figure 13 represented a reasonable simulation of the average in vivo conditions encountered in the patient studies. Consequently, singular importance must attach to comparison of the regression equation relating degree of fibrinogen proteolysis and thrombin clotting time obtained from the patient data (Figure 12) with that of in vitro experiment (Figure 13). To facilitate this comparison, the regression line from the patient studies is plotted (stippled line) in the right-hand panel of Figure 13 , where it is seen to lie in an intermediate position between the two slopes calculated from the in vitro data. Moreover, statistical testing indicated that the regression data from the patient studies did not differ significantly $(p>0.1)$ from either of the in vitro studies.

\section{Recovery from the effects of hyperplasminemia}

Clearance of fibrinogen proteolysis products from plasma. The data discussed in the last section of Figures 12 and 13 indicate that thrombin clotting times may be used to quantitate, with reasonable precision, the concentration of those fibrinogen proteolysis products in plasma causing the coagulation anomaly.

After the cessation of therapy in SK-treated patients, SK is rapidly cleared from the plasma (40) and plasma thrombolytic activity declines similarly. Consequently, serial thrombin clotting time determinations made during the postinfusion phase may be used to calculate the plasma clearance rate of the fibrinogen fragment(s) responsible for the coagulation anomaly. Thrombin clotting times were transformed into milligrams of fibrinogen digest products per milliliter of plasma, using the regression equations previously calculated (Figures 12 and 13). Concentration of breakdown products (on an exponential scale) was plotted against time in hours after cessation of infusion, and the 50 per cent plasma clearance rate of the breakdown products determined. Figure 14 displays the data for five patients and confirms the validity of the exponential plot.

The 50 per cent plasma clearance rate for the fibrinogen proteolysis products, calculated from the data of Figure 14 and that obtained from six other patients, ranged from 5 to 15 hours and averaged 9.6 hours. In general, the 50 per cent 


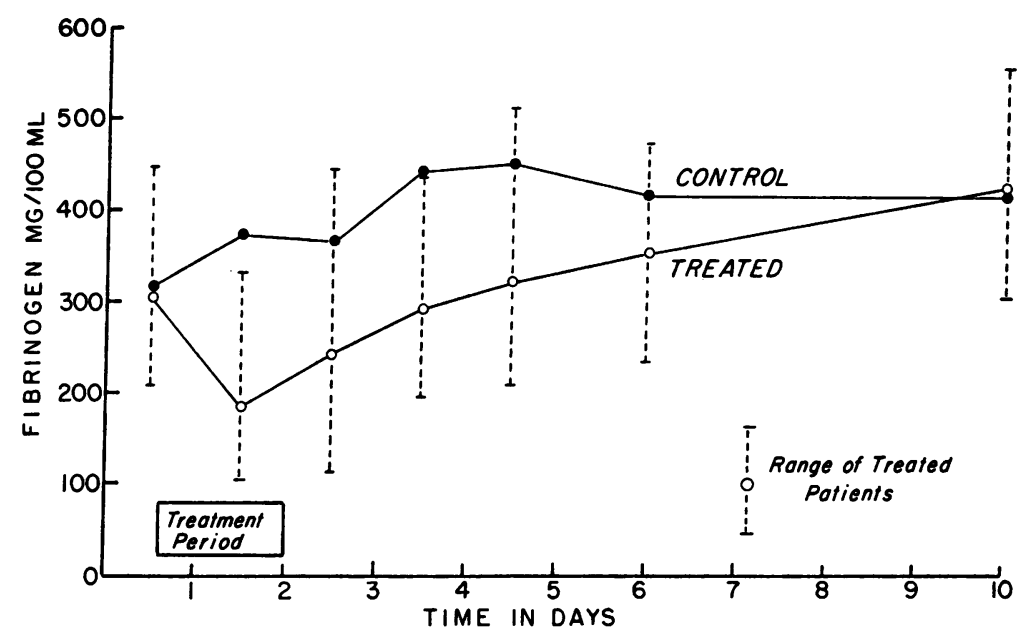

Fig. 15. Daily PLASMa FIBRINOGEN DETERMinations IN TWO SERIES OF PATIENTS. The control series suffered from early acute myocardial infarction (observation commenced within 14 hours of infarction); the treated series were a similar group of patients, who had received intensive SK treatment for 30 hours. Mean values are given for control patients, and mean and range for the treated series.

plasma clearance rate was faster when the coagulation anomaly was of an extreme nature; this phenomenon is seen in Figure 14 in which the two patients who developed severe coagulation defects had 50 per cent plasma clearance rates approximately double those recorded for the other three patients who developed only a moderate degree of coagulation defect.

Recovery from hypofibrinogenemia. Recovery from hypofibrinogenemia, even when this state has been of prolonged duration, is relatively rapid. Figure 15 shows the mean and range of plasma fibrinogen values in eight patients who received intensive thrombolytic therapy for 30 hours. All developed hypofibrinogenemia, the average plasma fibrinogen falling from 300 to $190 \mathrm{mg}$ per $100 \mathrm{ml}$. After cessation of therapy, plasma fibrinogen levels rose substantially in 24 hours and had reached control levels by 48 hours. Since the treated patients were suffering from acute myocardial infarction in which an early rise in plasma fibrinogen almost invariably occurs, plasma fibrinogen values for seven similarly afflicted untreated patients have also been plotted in Figure 15. These control values showed the expected rise as a consequence of the disease process itself; over the first 3 days of hospitalization the fibrinogen rose from 320 to $440 \mathrm{mg}$ per $100 \mathrm{ml}$ in an approxi- mately linear fashion with time. This rate of increase is approximately the same as in the SKtreated patients.

Recovery rates from hypofibrinogenemia in these latter patients did not differ significantly $(p>0.1)$ from other SK-treated patients not suffering from myocardial infarction (19). Thus, in three classes of patients-those suffering from myocardial infarction, those with hypofibrinogenemia induced by SK treatment, and those suffering from both conditions-plasma fibrinogen rose at the rate of 40 to $55 \mathrm{mg}$ per $100 \mathrm{ml}$ daily. These findings suggest that the patients may have been subjected to a maximal stimulus as regards fibrinogen synthesis and mobilization from extravascular spaces. Consequently, it may be inferred that in conditions unaccompanied by gross disturbance of plasma volume the maximal rate of plasma fibrinogen replacement in the human is of the order of $1.5 \mathrm{~g}$ fibrinogen in 24 hours. Since there is evidence that fibrinogen in the extra- and intravascular spaces is in equilibrium and the amount contained in the two compartments is approximately equal (41), it is probable that the patients were synthesizing fibrinogen at the rate of $3 \mathrm{~g}$ per 24 hours. The normal rate of plasma fibrinogen turnover is approximately 17 per cent in 24 hours (41-43), and these findings suggest 
that under these experimental conditions the rate of fibrinogen synthesis, or mobilization, or both, had been approximately doubled.

\section{DISCUSSION}

The etiological factor ( $\mathrm{s}$ ) involved in the genesis of pathological proteolytic states has been the subject of considerable investigation, but precise knowledge as to the importance of various etiological factors has yet to be obtained. Clinically these states may present either on account of a single etiological cause, as in that variety iatrogenically induced as a consequence of thrombolytic therapy $(19,22)$ and studied in this communication, or as a complex problem of multifactorial pathogenesis, which may involve hyperplasminemia, intravascular coagulation, thrombolysis, depletion of coagulation factors through hemorrhage, and other complications. However, the latter syndrome of complex etiology, which arises secondarily to the presence of disease, operative trauma or other stress, does exhibit many features in common with the iatrogenically induced form; the relationship between the two will be discussed after consideration of the iatrogenic form.

It has long been observed that "purified" fibrinogen solutions, on storage at various temperatures $\left(0\right.$ to $\left.37^{\circ} \mathrm{C}\right)$ slowly or rapidly (depending on the particular fibrinogen preparation and the temperature) become resistant to the clotting action of thrombin (in conventional nomenclature, develop "antithrombin" activity) and finally become incoagulable. Seegers, Nieft and Vandenbelt (44), who first investigated this problem in a systematic way, demonstrated that during this process at least two electrophoretically separable components ( $\alpha$ and $\beta$ derivatives) were formed and they suggested that this action was a consequence of contamination with fibrinolysin (plasmin).

Recently there has been renewed interest in the actions of fibrinogen proteolysis products on the coagulation system. Niewiarowski and Kowalski (45) studied digests of fibrinogen produced by plasmin action, and Triantaphyllopoulos (46-48) investigated the products arising after the spontaneous dissolution of fibrinogen (presumably similar products); both groups partially purified the active material by ammonium sulfate fraction- ation and concluded that the fibrinogen digest products exerted an antithrombin action. Independently, they concluded, as a result of animal experiment [respectively using the cat (45) and the rabbit (48)], that in vivo the products of fibrinogen proteolysis interfere sufficiently with thrombin action to produce a coagulation defect. However, the relevance of these experiments to human pathological states was not established.

Ideally, the contention that hyperplasminemia causes a specific coagulation defect related to the presence of fibrinogen digest products in plasma should be supported by evidence demonstrating that: 1) the characteristics of the clinically occurring defect can be reproduced by adding fibrinogen proteolysis products to plasma in vitro; 2) the putative digest product should be demonstrated in plasma showing the defect; 3 ) the magnitude of the defect should be related to the extent of fibrinogen proteolysis in vivo and correlated with the degree of hyperplasminemia ; 4) the extent of the defect should be shown to be at least relatively independent of final plasma fibrinogen concentration; 5) calculations made from in vitro data should be shown to be relevant to prediction of the in vivo coagulation anomaly; 6) the active principle(s) should be isolated from the fibrinogen digest; and 7) the biochemical mechanisms underlying the coagulation defect should be elucidated. Since the experimental hypothesis (vide supra) can be established by fulfillment of requirements 1 through 5 , the present communication is restricted to their investigation; the isolation of the active principle from the fibrinogen digest and the demonstration of its biochemical actions is the subject of an accompanying communication (25).

The evidence displayed in Figures 6-9 indicates that all the features of the clinical coagulation defect (with the obvious exceptions of fibrinogen and Factor $\mathrm{V}$ fall, which are direct proteolytic effects) can be simulated in vitro by the addition of fibrinogen proteolysis products to plasma, while the clinical and other in vitro studies demonstrated that the magnitude of the coagulation defect was related to the extent of fibrinogen proteolysis, which correlated with the degree of hyperplasminemia. Although the electrophoretic data relating to the presence of the putative fibrinogen proteolysis products in plasma with the coagulation de- 
fect can only be interpreted in a semiquantitative manner, the evidence substantiates the hypothesis under test. The finding that the $F_{1}$ (Kekwick) fraction of plasma, exhibiting the coagulation defect, prolonged the thrombin clotting time of the test systems and showed the electrophoretic stigmata characteristic of fibrinogen proteolysis products is excellent evidence that the former property of plasma depended upon the presence of the latter component $(s) . \quad F_{1}$ fractions prepared from normal plasma exhibited neither of these properties, and fractions ${ }^{18}$ other than $F_{1}$ component, prepared from plasma exhibiting the defect, neither prolonged the thrombin clotting time of the test system nor revealed the presence of fibrinogen proteolysis products on electrophoresis.

The evidence also indicates that hyperplasminemia-developing in plasma and caused by adding plasminogen activator in vitro (49), infusing it in vivo $(19,21,22)$, or inducing its in vivo release by pharmacological means or stress (50)is a complex equilibrium state governed by a number of simultaneously occurring reactions involving activation, inhibition and the formation of enzyme-substrate complexes. Under physiologic conditions, antiplasmin inhibitor is in excess, ${ }^{19}$ a phenomenon accounting for our previous inability $(20)$ to demonstrate more than trace amounts of plasmin in the plasma of streptokinasetreated patients. Moreover platelets themselves, or proteins adsorbed to their surface constitute an important additional reservoir of plasma antiplasmin (51). Thus, only susceptible or abundant substrates, or both, are liable to degradation under in vivo conditions (a phenomenon accounting for the apparently preferential enzymatic digestion of fibrinogen and the self-limited nature of the state).

Assays for specific coagulation factors (except Factor V, prothrombin, fibrinogen, and related moieties) were not performed on the patient sam-

\footnotetext{
18 Except only the original plasma supernatant from $F_{1}$ fractionation, which contained approximately 85 per cent of the original protein and could not be satisfactorily examined by electrophoretic methods.

${ }^{19}$ It is unknown whether this biochemical relationship always obtains in clinical practice. Occasionally patients, often suffering from carcinoma of the prostate with metastases, exhibit long sustained and severe manifestations of excessive plasma proteolysis. Serial antiplasmin levels in such patients have not been reported.
}

ples, because the stage of the coagulation reaction studied, fibrinogen-fibrin conversion, is not influenced by these factors. However, the possible relevance of specific factor depletion in the genesis of the over-all coagulation defect produced by hyperplasminemia merits brief comment. Plasmin, in addition to degrading fibrinogen and fibrin, also degrades other specific coagulation factors (52$58)$; there is agreement that Factors V and VIII may be destroyed, but disagreement as to whether Factors VII, IX, and prothrombin are susceptible to enzymatic degradation.

We have previously reported that in a similar group of SK-treated patients Factor V concentration fell to approximately 50 per cent of normal, but that neither prothrombin, measured by the two-stage technique, nor the platelet count, was reduced. These findings were confirmed in the present series and in agreement with the results of Donaldson (55), who in an extensive in vitro study found that the only consistent specific coagulation factor depletion occurring as a consequence of streptokinase addition to plasma related to Factor $\mathrm{V}$ concentration. Moreover, recalcification times remained within normal limits in the present series of patients, suggesting that those initial coagulation stages, dependent upon the presence of specific coagulation factors, were not grossly disturbed. This finding is consistent with that of Coon and Duff (54), who demonstrated in dogs treated with thrombolytic agents that thromboplastin generation was unaltered until fibrinogen was greatly reduced. Consequently, it is unlikely that important depletion of specific coagulation factors complicated the coagulation anomaly due to fibrinogen proteolysis observed in our patients.

Although we conclude that the main direct etiological agent in the genesis of the coagulation defect due to hyperplasminemia is the fibrinogen proteolysis product, the biochemical mechanism by which coagulation is inhibited has not been investigated in detail. We have already indicated ${ }^{12}$ that there is cause for dissatisfaction with the present restricted nomenclature by which substances such as fibrinogen proteolysis products, which prolong the thrombin clotting time (and consequently the one-stage prothrombin time), are labeled antithrombin. Indeed the data (Figures 6-9) bearing on the properties of the inhibitor detected in 
the plasma of patients with the defect and in plasma containing fibrinogen proteolysis products do not suggest that the plasmas exhibited true antithrombin activity. The coagulation anomaly can not be diluted out (Figure 8), or corrected with either excess thrombin (Figure 7 ) or protamine sulfate (Figure 9). Moreover, it was demonstrated that whereas the addition of a known inhibitor of fibrin polymerization, urea (38), to plasma reproduced the anomaly exhibited by the patient samples, a thrombin inhibitor, TAMe (39), produced a different type of anomaly.

Consequently, the evidence shown in Figure 5, which illustrates the competitive relationship between concentration of breakdown products and thrombin clotting time, does not establish that fibrinogen proteolysis products competitively inhibit thrombin action in the absence of further evidence to establish the locus of action. The accompanying communication (25) will demonstrate that fibrinogen proteolysis products interfere with the polymerization of fibrin monomer, and that a uniquely determined coagulation disorder, termed defective fibrin polymerization, underlies the coagulation anomalies developing during the hyperplasminemic state.

These observations have clinical significance not only with respect to the pathogenesis of the hyperplasminemic coagulation defect but also with regard to its treatment. The demonstration that the 50 per cent plasma clearance rate of the abnormal fibrinogen fragment is approximately 9.5 hours indicates that the coagulation defect will spontaneously resolve provided that the hyperplasminemic state is controlled. ${ }^{20}$ Preliminary clinical trial with $\epsilon$-aminocaproic acid, an inhibitor of plasminogen activation $(29,59)$ which may be administered intravenously in high dosage, has yielded promising results $(60-62)$; as predicted, control of the abnormal plasma proteolysis is followed by a disappearance of the coagulation anomalies within a period of hours (12 to 24 hours).

The present investigation has been concerned with the pathogenesis of "pure" hyperplasminemia

${ }^{20}$ Parenthetically it may be noted (Figures 5 and 13) that the therapeutic effect of infusing fibrinogen in such patients may in part be due to the establishment of a ratio between fibrinogen and fibrinogen proteolysis products that permits relatively normal functioning of the coagulation system. of the type seen after its iatrogenic induction or after its in vitro simulation. Clinically, the spontaneously developing coagulation lesion that occurs after surgical intervention or in the course of obstetric complication is of complex etiology. As admirably demonstrated by Soulier and colleagues (4), the hyperplasminemia following surgical intervention is commonly the result of release of both plasminogen activator and thromboplastic material from the traumatized tissue. Similarly, particularly after the work of Schneider (10, 11) and others (6-9), it has been appreciated that the hyperplasminemic state complicating obstetric emergencies, particularly abruptio placenta, may arise, at least in part, secondarily to the release of thromboplastic material from the placental site. Characteristic of this latter group of patients, is a severe degree of hypofibrinogenemia (63), a profound reduction in platelet count $(6,7)$, and a fall in plasma concentration of specific coagulation factors $(6,7)$.

The association between release of thromboplastic material and plasminogen activator is exemplified by the results of two experimental studies involving hypovolemic shock. In one study a phase of accelerated coagulation with intravascular fibrin deposition was demonstrated (64), and in the other (65) the presence of plasminogen activator release. The individual and synergistic influence of both factors on the production of hypofibrinogenemia in the rabbit has also been studied (66). Moreover, the injection of thromboplastic material $(67,68)$ or thrombin $(69)$ into the dog produces both a coagulation defect of the type described in this communication and also a marked fall of plasma plasminogen with a concomitant considerable increase of plasma activator (70). Of particular interest in this connection is our demonstration (Figure 4) that plasmin hydrolyzes both fibrin and fibrinogen to produce proteolysis products exerting qualitatively and quantitatively similar effects on the coagulation system. Consequently, the release of both thromboplastic material and plasminogen activator might notably increase the severity of the coagulation defect through the rapid lysis of intravascular fibrin deposits. Such a combined release of thromboplastic material and plasminogen activator would be expected to produce particularly severe coagulation anomalies, of the type observed clinically in obstetric patients, 
since the rate of lysis of fibrin deposited in the presence of plasminogen activators greatly exceeds that of fibrinogenolysis $(19,20,71,72)$.

Hence evidence of plasminogen-plasmin system activity and a coagulation anomaly due to fibrinogen or fibrin proteolysis may appear and dominate the clinical picture in patients in whom the primary pathological insult was intravascular coagulation. Because the treatment of such patients, by measures directed against the largely secondary "fibrinolytic" state, may predispose the patient to clinical complications resulting from intravascular coagulation, the establishment of a presumptive etiological diagnosis prior to the institution of therapy is important.

\section{SUMMARY}

1. Patients undergoing treatment with plasminogen activators administered by the intravenous route (thrombolytic therapy) may develop a coagulation defect similar in its main characteristics to that observed in patients, who "spontaneously" develop states of pathological plasma proteolytic activity (pathological "fibrinolytic" states).

2. Digests prepared from purified fibrinogen or from fibrin by plasmin or trypsin action will, on addition to plasma or fibrinogen solutions, inhibit their clotting by thrombin. Addition of such digests to plasma in vitro reproduces the coagulation anomaly developing in patients receiving thrombolytic therapy. Furthermore, both in patients and in vitro, plasma fractionation studies followed by electrophoresis permit the identification of new molecular species, formed from fibrinogen, which reproduce the defect in in vitro assay systems.

3. Studies in patients demonstrate that the observed degree of fibrinogen proteolysis suffices to account, on a quantitative basis, for the entire degree of major coagulation anomaly which develops.

4. It is suggested that the major coagulation defect, developing during states of pathological plasma proteolytic activity, relates to the presence of proteolysis products, formed from fibrinogen or fibrin which circulate in plasma.

\section{APPENDIX}

Diagnosis of the hyperplasminemic state. The findings reported here and previously (24) suggest that current concepts concerning the significance of certain laboratory criteria employed to establish the diagnosis of hyperplasminemia may need revision. Because the coagulation findings in this disorder, considered apart, are nonspecific (73), their etiological significance can only be established by demonstration of concomitant alterations in plasminogen-plasmin system activity.

Endogeneously released plasminogen activator contained in plasma is highly unstable at $37^{\circ} \mathrm{C}(50)$ and in vivo investigation has demonstrated that its appearance in plasma may be transient; high levels of activity often persisting for only a few minutes (34). Consequently, in clinical practice where laboratory tests to establish the diagnosis of hyperplasminemia are usually requested some time after the onset of a hemorrhagic diathesis, reliance cannot be placed upon nor does the diagnosis rest upon the detection in high concentrations of the etiological agent, plasminogen activator, in plasma. In our experience, using quantitative assay methods (70), the plasminogen activator content of such specimens is usually raised, but only within the range 2 - to 10 -fold greater than normal values. Occasionally, when the clinical onset has been sudden, levels of 20 to 100 times normal may be assayed; conversely, although rare, plasminogen activator activity may be within the normal range but all other diagnostic criteria are satisfied (vide infra).

Fortunately, plasminogen activator release of sufficient degree to cause hyperplasminemia produces other changes of reliable diagnostic value. Chief of these is a substantial fall of plasma plasminogen; the finding of values below 2 casein $U$ per $\mathrm{ml}$ plasma is an invaluable diagnostic indication of recent hyperplasminemia, and in many patients values as low as 1.0 to $0.5 \mathrm{C}$ per $\mathrm{ml}$ may be found. Assay for the enzyme plasmin, for the reasons advanced previously (20) and examined in the first section of this paper, is not normally valuable, although some small increase of plasma esterase activity (BAMe and TAMe substrates) may sometimes be detected.

The coagulation defect occurring as a consequence of hyperplasminemia has been the subject of this paper, and its demonstration plus the finding of decreased plasma plasminogen together with some increase of plasma activator permits a diagnosis of hyperplasminemia. However, it is emphasized that marked increase of plasma activator may be lacking and the diagnosis may occasionally be made in its absence. Parenthetically it may be noted that this latter situation (a coagulation defect with lowered plasma plasminogen, but with no demonstrable excess of plasminogen activator in the plasma) is most clearly seen in streptokinase-treated patients after cessation of therapy (19), where the induced coagulation defect and the lowered plasminogen persist for many hours after all evidence of plasma thrombolytic activity has disappeared.

\section{ACKNOWLEDGMENTS}

It is a pleasure to record our indebtedness to Mrs. Odessa Turner and Mr. Arthur Sommer for technical assistance. 


\section{REFERENCES}

1. Sherry, S., Fletcher, A. P., and Alkjaersig, N. Fibrinolysis and fibrinolytic activity in man. Physiol. Rev. 1959, 39, 343.

2. Scott, E. V. Z., Matthews, W. F., Butterworth, C. E., Jr., and Frommeyer, W. B., Jr. Abnormal plasma proteolytic activity: Diagnosis and treatment. Surg. Gynec. Obstet. 1954, 99, 679.

3. Ratnoff, O. D. Studies on a proteolytic enzyme in human plasma. VII. A fatal hemorrhagic state associated with excessive plasma proteolytic activity in a patient undergoing surgery for carcinoma of the head of the pancreas. J. clin. Invest. 1952, 31, 521.

4. Soulier, J. P., Mathey, J., Le Bollock, A. G., Daumet, $P$., and Fayet, H. Syndrome hémorrhagiques mortels avec incoagulabilité totale par défibrination et avec fibrinolyse. 1. Au cours des exérèses pulmonaires. Rev. Hémat. 1952, 7, 30.

5. von Kaulla, K. N., and Swan, H. Clotting deviations in man during cardiac bypass: Fibrinolysis and circulating anticoagulant. J. thorac. Surg. 1958, 36, 519.

6. Ratnoff, O. D., Pritchard, J. A., and Colopy, J. E. Medical progress: Hemorrhagic states during pregnancy. New Engl. J. Med. 1955, 253, 63, 97.

7. Ratnoff, O. D., and Holland, T. R. Coagulation components in normal and abnormal pregnancies. Ann. N. Y. Acad. Sci. 1959, 75, 626.

8. Phillips, L. L. Etiology of afibrinogenemia : Fibrinogenolytic and fibrinolytic phenomena. Ann. N. Y. Acad. Sci. 1959, 75, 676.

9. Pritchard, J. A., and Wright, M. R. Pathogenesis of hypofibrinogenemia in placental abruption. New Engl. J. Med. 1959, 261, 218.

10. Schneider, C. L. Fibrination and defibrination in Physiologie und Pathologie der Blutgerinnung in der Gestations Periode. Stuttgart, SchattauerVerlag, 1957.

11. Schneider, C. L. Etiology of fibrinopenia: Fibrination-defibrination. Ann. N. Y. Acad. Sci. 1959, 75, 634.

12. Dillard, G. H. L., and Chanutin, A. The protease and antiprotease of plasmas of patients with cancer and other diseases. Cancer Res. 1949, 9, 665.

13. Aboulker, P., Soulier, J. P., and Larrieu, M. J. Syndrome hémorrhagique avec fibrinolyse associé au cancer de la prostate. Presse méd. 1955, 63, 353.

14. Tagnon, H. J., Whitmore, W. F., Jr., Schulman, P., and Kravitz, S. C. The significance of fibrinolysis occurring in patients with metastatic cancer of the prostate. Cancer 1953, 6, 63.

15. Bergström, K., Blombäck, B., and Kleen, G. Studies on the plasma fibrinolytic activity in a case of liver cirrhosis. Acta med. scand. 1960, 168, 291.

16. Beaumont, J. L., Beaumont, V., and Domart, A. Recherches sur l'activité fibrinolytique spontanée du plasma dans les cirrhoses du foie. Rev. franç Et. clin. biol. 1956, 1, 667.

17. Kwaan, H. C., McFadzean, A. J. S., and Cook, J. On plasma fibrinolytic activity in cryptogenic splenomegaly. Scot. med. J. 1957, 2, 137.

18. Ratnoff, O. D. Studies on a proteolytic enzyme in human plasma. IV. The rate of lysis of plasma clots in normal and diseased individuals, with particular reference to hepatic disease. Bull. Johns Hopk. Hosp. 1949, 84, 29.

19. Fletcher, A. P., Alkjaersig, N., and Sherry, S. The maintenance of a sustained thrombolytic state in man. I. Induction and effects. J. clin. Invest. 1959, 38, 1096.

20. Alkjaersig, N., Fletcher, A. P., and Sherry, S. The mechanism of clot dissolution by plasmin. J. clin. Invest. 1959, 38, 1086.

21. Deutsch, E., and Fischer, M. Die Wirkung intravenös applizierter Streptokinase auf Fibrinolyse und Blutgerinnung. Thromb. Diath. haemor. 1960, 4, 482.

22. Johnson, A. J., and McCarty, W. R. The lysis of artificially induced intravascular clots in man by intravenous infusions of streptokinase. J. clin. Invest. 1959, 38, 1627.

23. Fletcher, A. P., Sherry, S., Alkjaersig, N., Smyrniotis, F. E., and Jick, S. The maintenance of a sustained thrombolytic state in man. II. Clinical observations on patients with myocardial infarction and other thromboembolic disorders. J. clin. Invest. 1959, 38, 1111.

24. Fletcher, A. P. The pathophysiology of thrombolysis in Proc. of the Conference on Thrombolytic Agents (Chicago, 1960), H. R. Roberts and J. D. Geratz, Eds. Chapel Hill, University of North Carolina, 1960.

25. Alkjaersig, N., Fletcher, A. P., and Sherry, S. Pathogenesis of the coagulation defect developing during pathological plasma proteolytic ("fibrinolytic") states. II. The significance, mechanism and consequences of defective fibrin polymerization. J. clin. Invest. 1962, 41, 917.

26. Kekwick, R. A., Mackay, M. E., Nance, M. H., and Record, B. R. The purification of human fibrinogen. Biochem. J. 1955, 60, 671.

27. Alkjaersig, N., Fletcher, A. P., and Sherry, S. The activation of human plasminogen. I. Spontaneous activation in glycerol. J. biol. Chem. 1958, 233, 81 .

28. Troll, W., and Sherry, S. The activation of human plasminogen by streptokinase. J. biol. Chem. 1955, 213, 881.

29. Alkjaersig, N., Fletcher, A. P., and Sherry, S. e-Aminocaproic acid: An inhibitor of plasminogen activation. J. biol. Chem. 1959, 234, 832.

30. Kekwick, R. A., and Mackay, M. E. The Separation of Protein Fractions from Human Plasma by Ether. (Medical Research Council Special Reports no. 286.) London, Her Majesty's Stationery Office; 1954. 
31. Lever, W. F., Gurd, F. R. N., Uroma, E., Brown, R. K., Barnes, B. A., Schmid, K., and Schultz, E. L. Chemical, clinical, and immunological studies on the products of human plasma fractionation. XL. Quantitative separation and determination of the protein components in small amounts of normal human plasma. J. clin. Invest. 1951, 30, 99.

32. Seegers, W. H., and Smith, H. P. Factors which influence the activity of purified thrombin. Amer. J. Physiol. 1942, 137, 348.

33. Ratnoff, O. D., and Menzie, C. A new method for the determination of fibrinogen in small samples of plasma. J. Lab. clin. Med. 1951, 37, 316.

34. Sawyer, W. D., Fletcher, A. P., Alkjaersig, N., and Sherry, S. Studies on the thrombolytic activity of human plasma. J. clin. Invest. 1960, 39, 426.

35. International Committee on Blood Clotting Factors. Nomenclature of blood clotting factors. Thromb. Diath. haemor. 1959, 3, 435.

36. International Committee on Blood Clotting Factors. New blood clotting factors. Thromb. Diath. haemor. 1960, 4, suppl.

37. Brownlee, K. A. Industrial Experimentation, 4th ed. London, Her Majesty's Stationery Office, 1949.

38. Edsall, J. T., and Lever, W. F. Effect of ions and neutral molecules on fibrin clotting. J. biol. Chem. 1951, 191, 735.

39. Sherry, S., Troll, W., and Glueck, H. Thrombin as a proteolytic enzyme. Physiol. Rev. 1954, 34, 736.

40. Fletcher, A. P., Alkjaersig, N., and Sherry, S. The clearance of heterologous protein from the circulation of normal and immunized man. J. clin. Invest. 1958, 37, 1306.

41. Gitlin, D., and Borges, W. H. Studies on the metabolism of fibrinogen in two patients with congenital afibrinogenemia. Blood 1953, 8, 679.

42. Ingram, G. I. C., Pinniger, J. L., and Vallet, L. Survival in an afibrinogenaemic subject of fibrinogen prepared from "time-expired" blood. Lancet 1960, 1, 135.

43. Volwiler, W., Goldsworthy, P. D., MacMartin, M. P., Wood, P. A., Mackay, I. R., and Freemont-Smith, $\mathrm{K}$. Biosynthetic determination with radioactive sulfur of turnover rates of various plasma proteins in normal and cirrhotic man. J. clin. Invest. 1955, 34, 1126.

44. Seegers, W. H., Nieft, M. L., and Vandenbelt, J. M. Decomposition products of fibrinogen and fibrin. Arch. Biochem. 1945, 7, 15.

45. Niewiarowski, S., and Kowalski, E. Un nouvel anticoagulant dérivé du fibrinogène. Rev. Hémat. 1958, 13, 320.

46. Triantaphyllopoulos, D. C. Anticoagulant effect of incubated fibrinogen. Canad. J. Biochem. 1958, 36, 249.

47. Triantaphyllopoulos, D. C. Nature of the thrombin- inhibiting effect of incubated fibrinogen. Amer. J. Physiol. 1959, 197, 575.

48. Triantaphyllopoulos, D. C. Effects of intravenous injections of the anticoagulant fraction of incubated fibrinogen on blood coagulation. Canad. J. Biochem. 1960, 38, 909.

49. Sawyer, W. D., Alkjaersig, N., Fletcher, A. P., and Sherry, S. A comparison of the fibrinolytic and fibrinogenolytic effects of plasminogen activators and proteolytic enzymes in plasma. Thromb. Diath. haemor. 1960, 5, 149.

50. Sherry, S., Lindemeyer, R. I., Fletcher, A. P., and Alkjaersig, N. Studies on enhanced fibrinolytic activity in man. J. clin. Invest. 1959, 38, 810.

51. Alkjaersig, N. The antifibrinolytic activity of platelets in International Symposium on Blood Platelets, Henry Ford Hospital, S. A. Johnson, R. W. Monto, J. W. Rebuck and R. C. Horn, Jr., Eds. Boston, Little, Brown, 1961.

52. Alagille, D., and Soulier, J. P. Action des enzymes protéolytiques sur le sang total "in vitro." Modifications des facteurs de coagulation et du complément. Sem. Hôp. Paris 1956, 32, 355.

53. Soulier, J. P., Alagille, D., and Larrieu, M. J. Modifications "in vivo" des facteurs de coagulation dans les fibrinolyses; valeur du déficit en proaccélérine pour le diagnostic des protéolyses frustes ou latentes. Sem. Hôp. Paris 1956, 32, 359.

54. Coon, W. A., and Duff, I. V. Effect of intravenous human plasmin on the blood clotting mechanism of the dog. J. Lab. clin. Med. 1958, 51, 381.

55. Donaldson, V. H. Effect of plasmin in vitro on clotting factors in plasma. J. Lab. clin. Med. 1960, $56,644$.

56. Lewis, J. H., Howe, A. C., and Ferguson, J .H. Thrombin formation. II. Effects of lysin (fibrinolysin, plasmin) on prothrombin Ac-globulin and tissue thromboplastin. J. clin. Invest. 1949, 28, 1507.

57. Niewiarowski, S., and Latallo, Z. Influence of plasmin on the first coagulation stage. Bull. Acad. pol. sci. C1. 2. 1957, 5, 219.

58. Seegers, W. H., and Loomis, E. C. Prothrombin and fibrinolysin. Science 1946, 104, 461.

59. Ablondi, F. B., Hagan, J. J., Philips, M., and De Renzo, E. C. Inhibition of plasmin, trypsin and the streptokinase-activated fibrinolytic system by $\epsilon$-aminocaproic acid. Arch. Biochem. 1959, 82, 153.

60. Sherry, S., Fletcher, A. P., Alkjaersig, N., and Sawyer, W. D. $\epsilon$-aminocaproic acid, a potent antifibrinolytic agent. Trans. Ass. Amer. Phycns 1959, 72, 62.

61. Nilsson, I. M., Sjoerdsma, A., and Waldenstrom, J. Antifibrinolytic activity and metabolism of $\epsilon$-aminocaproic acid in man. Lancet 1960, 1, 1322.

62. McNicol, G. P., Fletcher, A. P., Alkjaersig, N., and Sherry, S. Impairment of hemostasis in the urinary tract: The role of urokinase. J. Lab. clin. Med. 1961, 58, 34. 
63. Sharp, A. A., Howie, B., Biggs, R., and Methuen, D. T. Defibrination syndrome in pregnancy; value of various diagnostic tests. Lancet 1958, 2, 1309.

64. Turpini, R., and Stefanini, M. The nature and mechanism of the hemostatic breakdown in the course of experimental hemorrhagic shock. J. clin. Invest. 1959, 38, 53.

65. Tagnon, H. J., Levenson, S. M., Davidson, C. S., and Taylor, F. H. L. The occurrence of fibrinolysis in shock, with observations on the prothrombin time and the plasma fibrinogen during hemorrhagic shock. Amer. J. med. Sci. 1946, 211, 88.

66. McKay, D. G., Kliman, A., and Alexander, B. Experimental production of afibrinogenemia and hemorrhagic phenomena by combined fibrinolysis and disseminated intravascular coagulation. New Engl. J. Med. 1959, 261, 1150.

67. Ratnoff, O. D., and Conley, C. L. Studies in afibrinogenemia. II. Defibrinating effect on dog plasma of intravenous injection of thromboplastic material. Bull. Johns Hopk. Hosp. 1951, 88, 414.
68. Lewis, J. H., Ferguson, E. E., and Schoenfeld, C. Studies concerning the turnover of fibrinogen $\mathrm{I}^{181}$ in the dog. J. Lab. clin. Med. 1961, 58, 247.

69. Monkhouse, F. C., and Milojevic, S. Changes in fibrinogen level after infusion of thrombin and thromboplastin. Amer. J. Physiol. 1960, 199, 1165.

70. Alkjaersig, N., Fletcher, A. P., and Sherry, S. Unpublished data.

71. Sherry, S. The fibrinolytic activity of streptokinase activated human plasmin. J. clin. Invest. 1954, 33, 1054.

72. Ratnoff, O. D. Studies on a proteolytic enzyme in human plasma. IX. Fibrinogen and fibrin as substrates for the proteolytic enzyme of plasma. J. clin. Invest. 1953, 32, 473.

73. Margolius, A., Jr., Jackson, D. P., and Ratnoff, O. D. Circulating anticoagulants: A study of 40 cases and a review of the literature. Medicine (Baltimore) $1961,40,145$. 